\title{
Horseradish Peroxidase-Carrying Electrospun Nonwoven Fabrics for the Treatment of o-Methoxyphenol
}

\author{
Chao Pan,, Ran Ding, ${ }^{1}$ Li Dong, ${ }^{2}$ Jing Wang, and Yucai Hu ${ }^{1}$ \\ ${ }^{1}$ College of Science, Dalian Ocean University, Dalian, Liaoning 116023, China \\ ${ }^{2}$ College of Science, Dalian Nationalities University, Dalian 116600, China \\ Correspondence should be addressed to Li Dong; dongli@dlnu.edu.cn
}

Received 3 July 2014; Revised 7 September 2014; Accepted 21 September 2014

Academic Editor: Yuqin Wan

Copyright (c) 2015 Chao Pan et al. This is an open access article distributed under the Creative Commons Attribution License, which permits unrestricted use, distribution, and reproduction in any medium, provided the original work is properly cited.

\begin{abstract}
The carboxyl-functionalized polystyrene (poly(styrene-co-methacrylic acid), PSMAA) nanofibers with average diameters of 250 $\pm 20 \mathrm{~nm}$ was prepared by electrospinning. PSMAA nanofibrous membrane were employed for immobilization of horseradish peroxidase (HRP) enzyme on the fibrous surface by a chemical method. The parameters about immobilizing HRP on the PSMAA nanofibers were studied and the influence on the activity of the HRP is discussed. This study showed that soap-free emulsion method is an ideal technology to modify the polystyrene surface and ultimately achieve enzyme immobilization on electrospun PSMAA nanofibers surfaces. Compared with free HRP, the acid-base stability, thermal stability, and storage stability of HRP were increased after the immobilization. The immobilized HRP maintained about $60 \%$ of its initial activity during a 20 -day storage period. However, the free HRP maintained only $40 \%$ of its initial activity. The removal percentages of o-methoxyphenol (OMP) reached $80.2 \%$ after $120 \mathrm{~min}$ for immobilized HRP. These results suggest that the proposed scheme for immobilization of HRP has potential in industrial applications for the treatment of phenolic wastewater.
\end{abstract}

\section{Introduction}

Horseradish peroxidase (HRP) has been shown to be able to remove a variety of phenols and aromatic amines from aqueous solutions [1-3]. However, the main drawback of treating wastewater by free HRP is its instability. To overcome this shortcoming, immobilization of HRP has been developed as an effective method for the applications of HRP, since it offered many advantages, such as increasing the stability of HRP and being repeatedly used easily $[4,5]$.

Electrospinning, being a simple and economical way to immobilize enzymes in situ, has received more and more attention in the last decade [6-10]. The appealing prospects of using electrospun fibrous membranes (EFMs) for enzyme immobilization include their tunable sizes (from micro to nanometer diameters), controllable morphology, high surface-to-volume ratio, and compositional variance. Thus, EFMs are regarded as a suitable support for the immobilization of enzymes. Recently, an application of immobilized HRP by electrospinning for removal of environmental pollutants from contaminated water has been reported. For example, Niu and coworkers [4] fabricated a HRP-immobilized poly(d,l-lactide-co-glycolide) (PLGA) fibers membrane for degradation of pentachlorophenol (PCP), obtaining removal efficiency of $83 \%$.

In preparations for enzyme membranes, it is difficult to get bulk active groups on the membrane surface. The traditional plasma surface physics modification [11, 12] is complex and fussy and it has only a low effect on increasing immobilization of enzymes. The chemical modification of electrospun fibers has been shown to be an effective immobilization method compared with the physics modification. For instance, there has been reported in immobilization procedures using chemical modification, which allows condensation reaction between the carboxyl groups on electrospun fibers and the side chain amino groups of enzyme molecules, leading to covalent bond formations between the fibrous surfaces and enzyme molecules [13]. The chemical binding for enzyme immobilization can be applied for the enzymes which do not adsorb onto the cationic matrix, and thus the matrix is used for immobilizing a wider range of enzyme species.

In this paper, poly(styrene-co-methacrylic acid) (PSMAA) random copolymer nanofibers, having carboxyl 


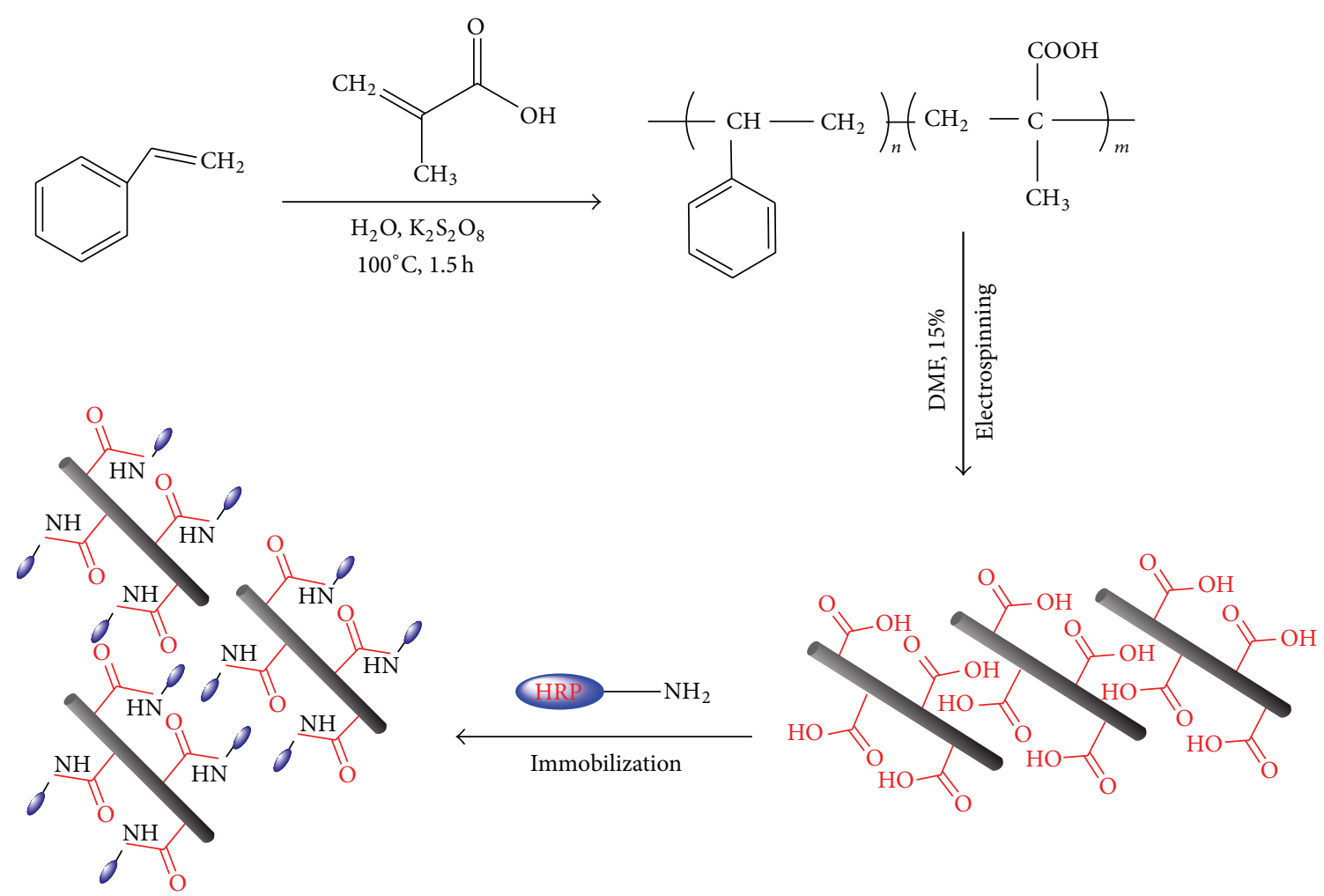

Scheme 1: Chemical route for synthesis of styrene-co-methacrylic acid copolymer and subsequent electrospinning nanofibers attachment of HRP.

groups on the MAA, were prepared by a combination of the soap-free emulsion polymerization method and an electrospinning technique (Scheme 1), which were employed as solid support to HRP enzyme, and immobilized HRP was used to remove OMP from water. The morphology, chemical structure of the PSMAA nanofibers, and the enzymatic properties of the immobilized HRP were investigated. The degradation efficiency of OMP by immobilized HRP was assessed.

\section{Experimental}

2.1. Materials. The materials were used without further purification. N,N-Dimethylformamide (DMF) and omethoxyphenol were purchased from the Shanghai Chemical Co. (China). The ingredients of phosphate buffer solution (PBS), such as orthophosphoric acid, dibasic sodium phosphate, and potassium phosphate monobasic, were of analytical grade and used as received. Horseradish peroxidase (HRP), Coomassie Brilliant Blue (G250), bovine serum albumin (BSA, molecular mass: 67,000 Da), phenol, 4aminoantipyrine, and pyrocatechol (1,2-dihydroxybenzene) were purchased from Sigma-Aldrich co., China. The water used in all experiments was prepared in a three-stage Millipore Milli-Q Plus 185 purification system (Richmond Scientific Ltd. Great Britain) and had a resistivity higher than $18.2 \mathrm{M} \Omega / \mathrm{cm}$.
The styrene (Sty) and methacrylic acid (MAA) monomers were purchased from the Lingfeng Chemical Co. (China). These chemicals were distilled under vacuum at $75^{\circ} \mathrm{C}$ before use.

2.2. Synthesis of Poly(styrene-co-methacrylic Acid). A typical synthesis was as follows: first, both Sty and MAA were distilled under vacuum at $75^{\circ}$ C. $25 \mathrm{~mL}$ Sty and $1.0 \mathrm{~mL}$ MAA were then mixed, and the mixture and $100 \mathrm{~mL}$ water were added into a three-mouth flask with condenser and mechanical stirrer. The mixture was stirred at a speed of $300 \mathrm{rpm}$ and heated under a heater cover. After $5 \mathrm{~min}$ of boiling, $0.1 \mathrm{~g}$ potassium persulfate powder (Sinopharm Chemical Reagent Co., Ltd, China) as initiator was added from the side mouth and the polymerization continued for 1.5 hours. The whole reaction was completed within 1.5 hours, with a conversion in excess of $90 \%$ (measured by the method of [14]). The resulting latex was cooled to ambient temperature and filtered through cheesecloth. The coagulum was dried and weighed.

2.3. Fabrication of PSMAA Nanofibers. A 15 wt.\% PSMAA solution was prepared by adding $1.5 \mathrm{~g}$ PSMAA powder to $8.5 \mathrm{~mL} \mathrm{DMF}$ at room temperature with magnetic stirring until it finally became a viscous precursor solution. The solution was quickly loaded into a $5 \mathrm{~mL}$ syringe equipped with a steel needle with a tip diameter of $0.5 \mathrm{~mm}$, whose tip was filed flat, which was connected to a high-voltage supply 


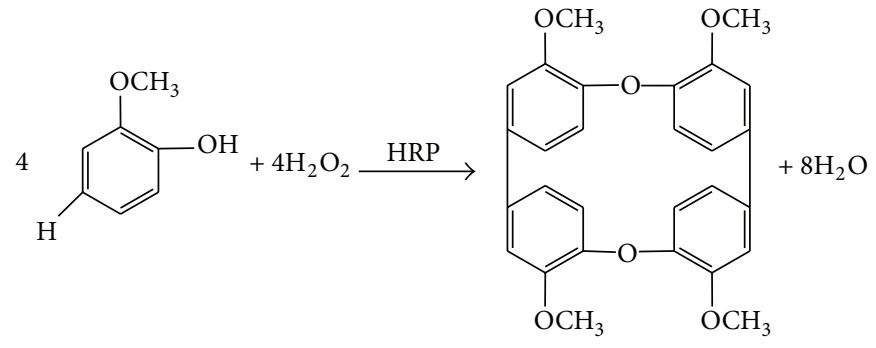

SCHEME 2

capable of generating voltage up to $30 \mathrm{kV}$. A copper wireframed drum collection screen was placed at a horizontal distance of $15 \mathrm{~cm}$ from the tip of the needle. The copper wire drum was connected to a motor with two pulleys and rotated at a speed of $300 \mathrm{rpm}$. The feeding rate of the precursor solution was controlled at $1 \mathrm{~mL} / \mathrm{h}$ using an automatic syringe pump so that a small drop was maintained at the capillary tip due to the surface tension of the solution. The solution on the tip of the needle was ejected under a strong electric field of the $20 \mathrm{KV}$, and the PSMAA fibers thus formed were dried initially for $5 \mathrm{~h}$ at $70^{\circ} \mathrm{C}$ under vacuum.

2.4. Immobilization of HRP. An appropriate amount of electrospun PSMAA nanofibrous membranes were immersed in $50 \mathrm{~mL}$ of BSA solution (1\% wt) for about $1.5 \mathrm{~h}$ at $20^{\circ} \mathrm{C}$ in shakers while stirring continuously and then thoroughly washed with deionized water to remove the residue BSA. Subsequently, the pretreated membranes were submerged into $20 \mathrm{~mL}$ of the HRP solution $(1 \mathrm{mg} / \mathrm{mL}$ in the PBS, $\mathrm{pH} 7.0$ ) in a $25 \mathrm{~mL}$ beaker and shaken gently in an ice bath for the required time. Finally, the membranes were taken out and washed with the PBS until no protein was detected in the washings.

2.5. Determination of Immobilization Capacity. The concentration of HRP in the solutions was determined by the method of Bradford [15] based on the absorbance of Coumassie Brilliant Blue reagent at $595 \mathrm{~nm}$ by UV-Visible spectroscopy (U-4100, Hitachi Co., Ltd, Japan). The amount of the bound enzyme was calculated as

$$
Q=\frac{\left(C_{0}-C\right) V}{m}
$$

where $Q$ is the amount of HRP bound onto unit mass of nanofibrous membranes $(\mathrm{mg} / \mathrm{g}), C_{0}$ and $C$ are the initial and equilibrium HRP concentrations in the solution $(\mathrm{mg} / \mathrm{mL}), V$ is the volume of the HRP solution, and $m$ is the mass of the nanofibrous membrane.

2.6. Characterization. The PSMAA nanofibers morphology was examined using (S-3000N, Hitachi, Co., Ltd, Japan) scanning electron microscope (SEM). All samples were sputter coated with gold. Fourier transform infrared (FTIR) spectra (BRUKER IFS66/S Perkin-Elmer) were recorded using pressed $\mathrm{KBr}$ pellets over the wavenumber range of
$4000-500 \mathrm{~cm}^{-1}$ at a resolution of $4 \mathrm{~cm}^{-1}$ to determine the PS and PSMAA.

2.7. Activity Measurements of HRP. The Worthington protocol was followed to calculate the activity of the HRP enzymes [15]. In this method, hydrogen peroxide $\left(\mathrm{H}_{2} \mathrm{O}_{2}\right)$, 4aminoantipyrene (4-AAP), and phenol were first mixed to form a colorless reagent and the HRP enzyme was immersed in the colorless reagent to catalyze the conversion of $\mathrm{H}_{2} \mathrm{O}_{2}$ to water, along with the conversion of the colorless dye to a red color (quinoneimine). The rate of color change was recorded by using UV-vis absorbance spectroscopy at $510 \mathrm{~nm}$, and the increase of absorbance was translated into enzyme activity through the specific absorptivity of the chromogen $\left(\varepsilon=7100 \mathrm{M}^{-1} \mathrm{~cm}^{-1}\right)$ [16]. The substrates used were 2.46 $\times 10^{-3} \mathrm{~mol} / \mathrm{L} 4$-AAP with $0.172 \mathrm{~mol} / \mathrm{L}$ phenol and $1.76 \times$ $10^{-3} \mathrm{~mol} / \mathrm{L} \mathrm{H}_{2} \mathrm{O}_{2}$. All measurements were in a PBS with a $\mathrm{pH}$ of 7.0. Each experiment was repeated three times.

2.8. Degradation Experiments. HRP-PSMAA $(1 \mathrm{~cm} \times 1 \mathrm{~cm}$, total weight $20 \pm 1 \mathrm{mg}$ ) membrane pieces were added one each to $10 \mathrm{~mL}$ solutions with the concentration of OMP at $8.06 \times$ $10^{-4} \mathrm{~mol} / \mathrm{L}$; the molar ratio of the reaction between OMP and $\mathrm{H}_{2} \mathrm{O}_{2}$ was about $1: 1$. The reaction scheme was suggested as shown in Scheme 2 [17, 18].

The mixture was incubated at $25 \pm 1{ }^{\circ} \mathrm{C}$ and $\mathrm{pH} 6.0$ under reciprocal agitation at 30 rounds per minute. For the purpose of terminating the HRP catalysis, $0.1 \mathrm{~mL}$ of $0.658 \mathrm{~mol} / \mathrm{L} \mathrm{H}_{3} \mathrm{PO}_{4}$ was added when sampling. The control experiment for free HRP was carried out in the same reactor using an equivalent amount of HRP. The OMP concentrations in the aqueous phase and on/in the HRP-PSMAA (washed by acetonitrile) were measured by a UV-vis spectrophotometer (U-4100, Hitachi Co., Ltd, Japan) at $470 \mathrm{~nm}$. The amount of OMP degraded by HRP was calculated by

$$
P \%=\frac{Q_{0}-Q_{S}}{Q_{0}} \times 100 \%,
$$

where $Q_{0}$ is the initial amount of OMP in solution and $Q_{S}$ is the amount of OMP retained in solution. All experiments were carried out at $25 \pm 1^{\circ} \mathrm{C}$.

\section{Results and Discussion}

3.1. FTIR Spectra of Copolymer. FTIR spectra of (a) the PS and (b) the PSMAA are shown in Figure 1; comparing these 


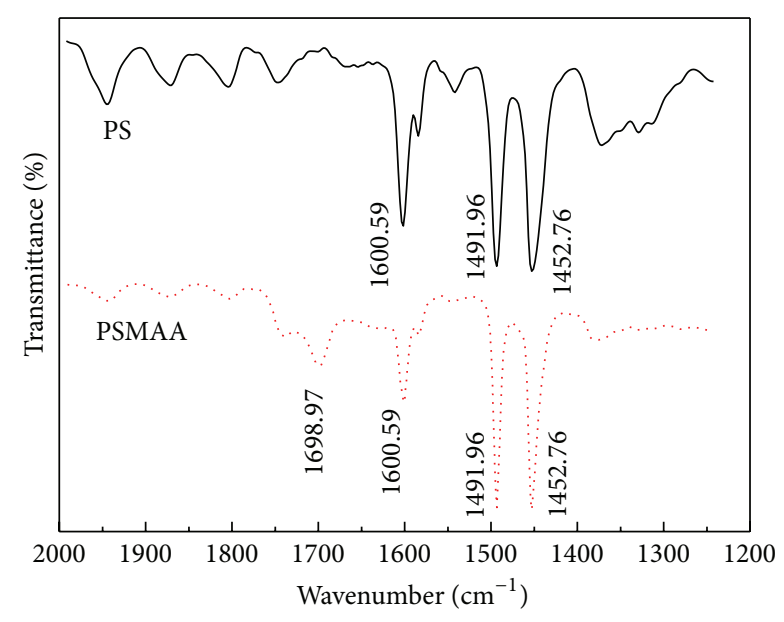

FIGURE 1: FT-IR spectrum of PS and PSMAA.

two spectra, the spectrum of the PSMAA membrane showed an absorbance band at $1698.97 \mathrm{~cm}^{-1}$, which is a characteristic band for carboxyl groups. It indicates that $\mathrm{COOH}$ groups of methacrylic acid have been blocked to styrene successfully.

3.2. The Surface Morphologies of the Nanofibrous Membrane. A SEM image of the original PSMAA nanofibers is displayed in Figure 2(a). The morphology of the nanofiber appears uniform, with the diameter of the nanofibers ranging from 230 to $270 \mathrm{~nm}$. After HRP immobilization, as shown in Figure 2(b), the diameter and the morphology of the nanofibers did not change substantially, although some of adhesion between the fibers compared with that un-immobilized. It might be because the $-\mathrm{COOH}$ groups of the PSMAA nanofibrous membranes reacted with amine groups of HRP protein, the bound protein then acted as a seed, and other unbound HRP molecules were adsorbed on the bound protein to form protein aggregation by molecular interactions.

\subsection{Effect of Immobilization Time on Enzyme Capacity and} Activity of HRP Immobilized on the PSMAA Nanofibers. To determine the optimum adsorption time, the effect of adsorption time on the immobilized amount of protein was studied. As shown in Figure 3, adsorption equilibrium was reached when the experiment running for $4 \mathrm{~h}$ and the activity of the immobilized HRP increased with prolonged coupling time, and the highest activity was obtained when immobilization was allowed to proceed for $4 \mathrm{~h}$. However, the activity decreased if the reaction time was longer; this might be because the long time coupling reaction to change unfolding degree of the enzyme molecule, resulting in a enzyme conformation is destroyed, causing inactivation of the enzyme. Therefore, to ensure the maximum adsorption of HRP onto the membranes, the adsorption time was adopted as $4 \mathrm{~h}$ in the following experiments.

3.4. Effect of Temperature on the Activity of HRP. The effect of temperature on the activity of free and immobilized HRP at $\mathrm{pH} 7.0$ is shown in Figure 4, the maximum activity of the free HRP appeared at $35^{\circ} \mathrm{C}$, but the optimum temperature of the immobilized HRP was slightly higher at $40^{\circ} \mathrm{C}$. At temperatures above $35^{\circ} \mathrm{C}$, as the temperature increased, the residual activity of the free HRP decreased faster than that of the immobilized HRP; that is, the immobilized HRP exhibited higher heat resistance than the free one. This is suggested to be due to interactions between enzyme and the PSMAA-COOH supports that limited the enzyme movement to reduce the degree of freedom of the spatial structure of enzyme, protecting it from deactivation at high temperatures.

3.5. Storage Stability. The storage stability of immobilized and free enzyme is presented in Figure 5 and the residual activity of immobilized and free HRP was $87.4 \%$ and $45.4 \%$ after 5 days, respectively. The results indicated that the storage stability of immobilized HRP was better than that of free HRP, which is suggested to be due to the immobilization of the enzyme limiting the freedom of conformational changes, resulting in increasing stability towards denaturalization [19].

3.6. Effect of $p H$ on the Activity of HRP. Figure 6 shows the effect of $\mathrm{pH}$ on the activity of the free and immobilized HRP. The optimal $\mathrm{pH}$ value was about 6.0 for both free and immobilized enzyme; no significant shift of the optimal $\mathrm{pH}$ was observed. But the residual relative activity of the immobilized HRP was higher than that of the free one at all other $\mathrm{pH}$ in the range between 2.0 and 9.0. The lower sensitivity of the immobilized enzyme to $\mathrm{pH}$ is probably because of a significant alteration of the enzyme microenvironment upon immobilization on the fibers.

3.7. o-Methoxyphenol (OMP) Removal by Free and Immobilized HRP. Figure 7 shows the efficiency of removal of OMP in a batch experiment running for $120 \mathrm{~min}$. The removal process by PSMAA-HRP was fast and reached a removal percentage of about $80.2 \%$. The removal efficiency of PSMAAHRP was higher than free HRP. This is suggested to be due to the fact that the OMP removal by immobilized enzyme was the result of both PSMAA nanofibers adsorption and enzymatic catalyzation; the OMP molecules diffuse from the bulk solution to the external surfaces of the PMAA nanofibers and adsorb onto the easily accessible hydrophobic sites on the surface. In addition a great amount of OMP was degraded by the HRP which is immobilized on the surface of fibers, and this step is usually assumed to be a fast one.

\section{Conclusion}

PSMAA nanofibrous membranes with uniform fiber diameters between 230 and $270 \mathrm{~nm}$ were prepared by an electrospinning method. HRP enzyme was successfully immobilized on the MAA carboxyl groups of the PSMAA nanofibers. The results of degradation experiments indicated that a removal efficiency of $80.2 \%$ was achieved. Immobilized HRP showed a better acid-base stability, thermal stability, and storage stability than free HRP, which is a very attractive aspect for real applications involving a sufficiently wide range of external conditions. 


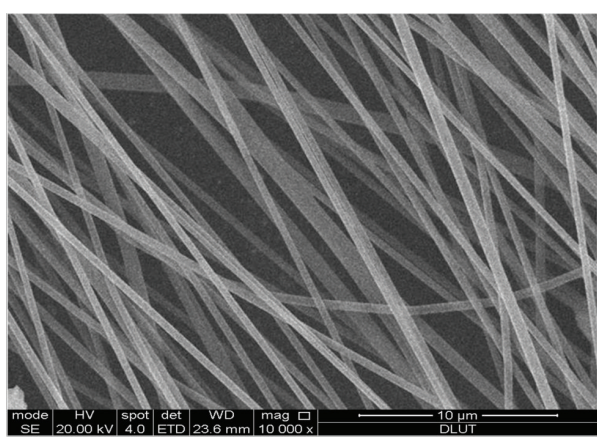

(a)

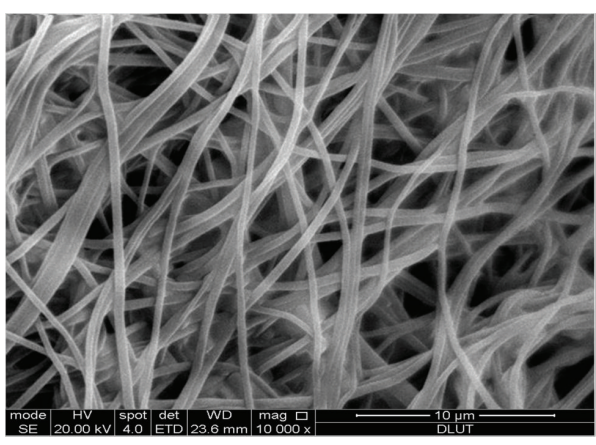

(b)

FIGURE 2: Morphologies of PSMAA nanofiber. (a) Original PSMAA nanofibers. (b) PSMAA nanofibers with immobilization of HRP.

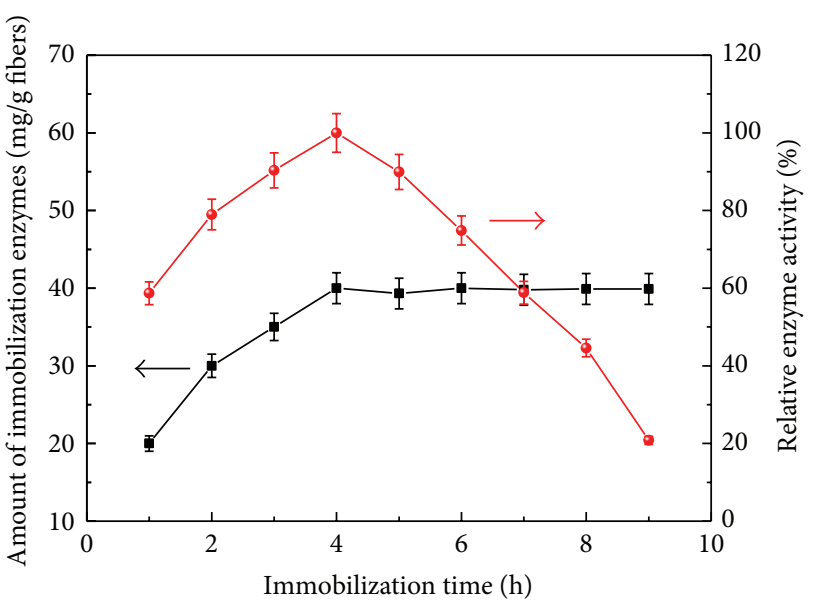

-- Immobilization enzyme ( $\mathrm{mg} / \mathrm{g}$ fibers)

- - Relative enzyme activity (\%)

FIGURE 3: Effect of immobilization time on enzyme loading capacity at $\mathrm{pH} 7.0$ and room temperature.

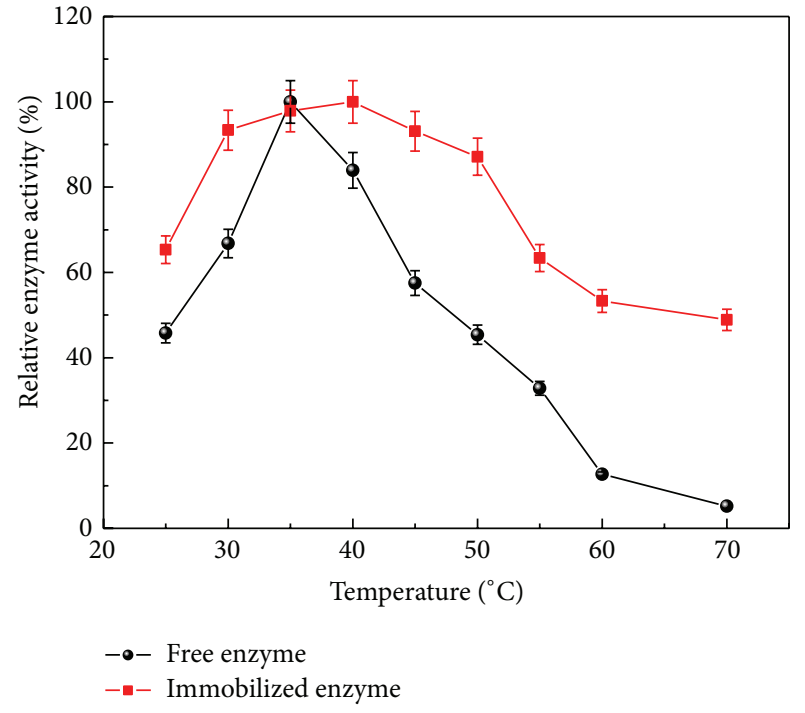

FIGURE 4: Effect of temperature on the activity of free and immobilized HRP.

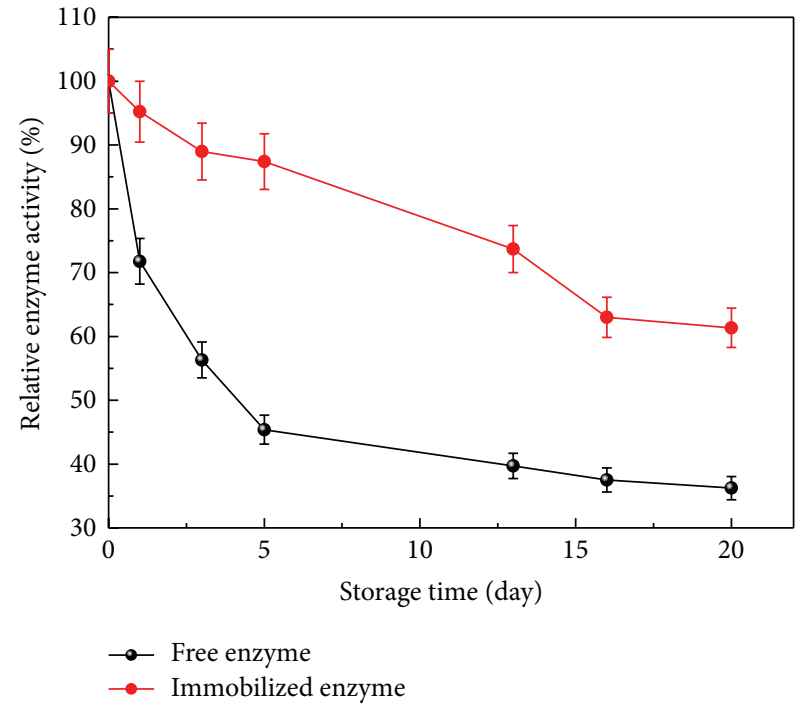

FIGURE 5: Storage stability of free and immobilized HRP.

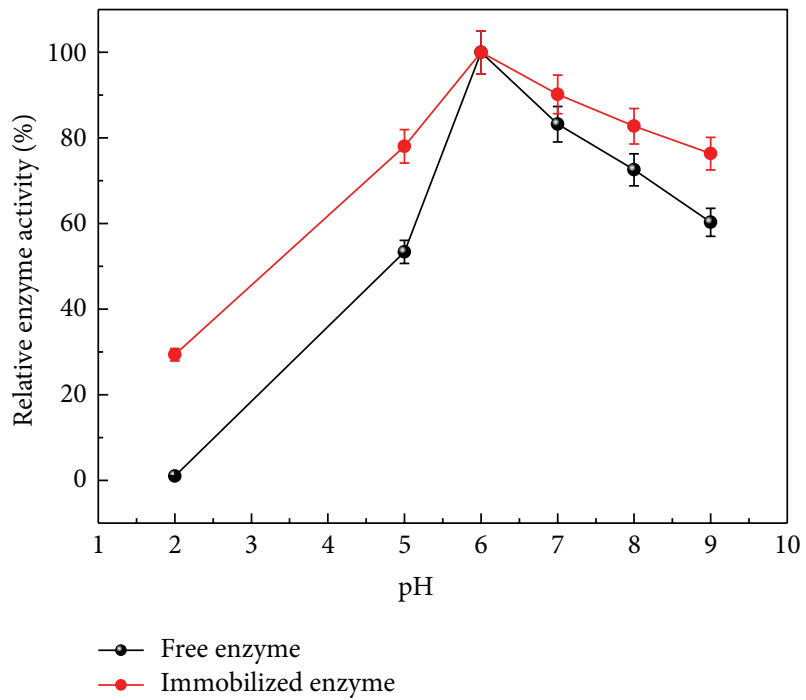

FIgURE 6: Effect of $\mathrm{pH}$ on the activity of HRP. 


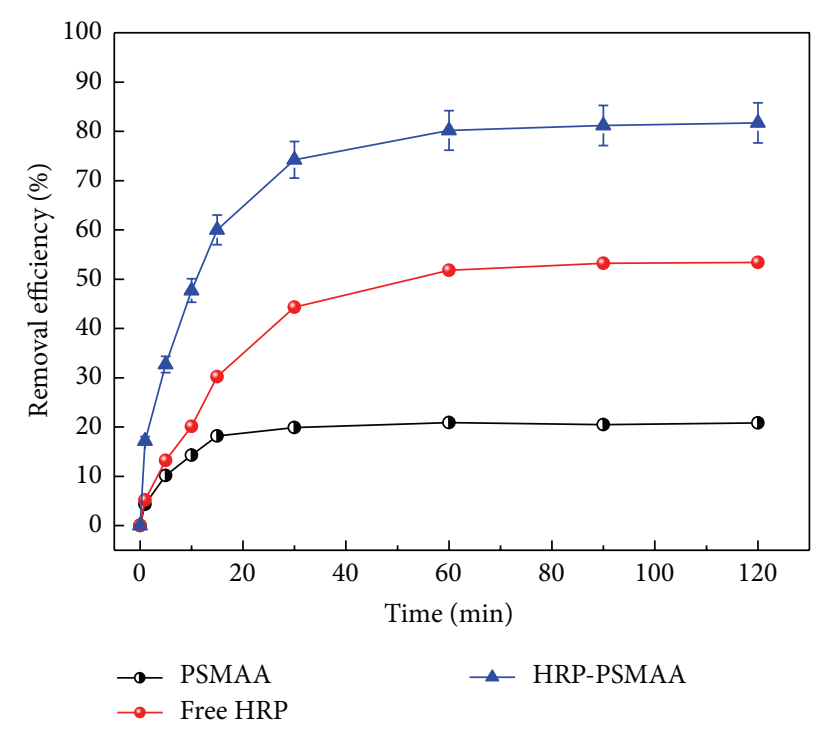

FIGURE 7: Degradation kinetics of OMP by PSMAA, free HRP, and HRP-PSMAA.

\section{Conflict of Interests}

The authors declare that there is no conflict of interests regarding the publication of this paper.

\section{Acknowledgments}

The authors acknowledge the financial support of the National Natural Science Foundation (no. 21102033), the Open Research Fund of MOIDAT (no. 201205), the Open Research Fund of State Key Laboratory of Fine Chemicals (no. KF1012), the Open Project Program of Key Laboratory of Ecotextiles, Ministry of Education, Jiangnan University (no. KLET1205), and the Scientific Research Fund of Liaoning Provincial Education Department (no. L2011122).

\section{References}

[1] A. M. Klibanov, T. M. Tu, and K. P. Scott, "Peroxidase-catalyzed removal of phenols from coal-conversion waste waters," Science, vol. 221, no. 4607, pp. 259-261, 1983.

[2] K. Tatsumi, S. Wada, and H. lchikawa, "Removal of chlorophenols from wastewater by immobilized horseradish peroxidase," Biotechnology and Bioengineering, vol. 51, no. 1, pp. 126-130, 1996.

[3] J. Cheng, S. Ming Yu, and P. Zuo, "Horseradish peroxidase immobilized on aluminum-pillared interlayered clay for the catalytic oxidation of phenolic wastewater," Water Research, vol. 40, no. 2, pp. 283-290, 2006.

[4] J. Niu, J. Xu, Y. Dai et al., "Immobilization of horseradish peroxidase by electrospun fibrous membranes for adsorption and degradation of pentachlorophenol in water," Journal of Hazardous Materials, vol. 246-247, pp. 119-125, 2013.

[5] J. Zhang, P. Ye, S. Chen, and W. Wang, "Removal of pentachlorophenol by immobilized horseradish peroxidase," International Biodeterioration and Biodegradation, vol. 59, no. 4, pp. 307-314, 2007.
[6] D. Han, S. Filocamo, R. Kirby, and A. J. Steckl, "Deactivating chemical agents using enzyme-coated nanofibers formed by electrospinning," ACS Applied Materials and Interfaces, vol. 3, no. 12, pp. 4633-4639, 2011.

[7] K. Sun and Z. H. Li, "Preparations, properties and applications of chitosan based nanofibers fabricated by electrospinning," Express Polymer Letters, vol. 5, no. 4, pp. 342-361, 2011.

[8] D. N. Tran and K. J. Balkus Jr., "Enzyme immobilization via electrospinning," Topics in Catalysis, vol. 55, no. 16-18, pp. 10571069, 2012.

[9] N. Amini, S. Mazinani, S.-O. Ranaei-Siadat, M. Kalaee, K. Niknam, and V. Adlfar, "Manufacturing polymethyl methacrylate nanofibers as a support for enzyme immobilization," Fibers and Polymers, vol. 13, no. 8, pp. 994-998, 2012.

[10] P. Ye, Z.-K. Xu, J. Wu, C. Innocent, and P. Seta, "Nanofibrous poly(acrylonitrile-co-maleic acid) membranes functionalized with gelatin and chitosan for lipase immobilization," Biomaterials, vol. 27, no. 22, pp. 4169-4176, 2006.

[11] O. G. Mouritsen, T. L. Andresen, A. Halperin et al., "Activation of interfacial enzymes at membrane surfaces," Journal of Physics Condensed Matter, vol. 18, no. 28, Article ID S1293, 2006.

[12] A. Kondyurin, N. J. Nosworthy, M. M. M. Bilek, R. Jones, and P. J. Pigram, "Surface attachment of horseradish peroxidase to nylon modified by plasma-immersion ion implantation," Journal of Applied Polymer Science, vol. 120, no. 5, pp. 2891-2903, 2011.

[13] H. Jia, G. Zhu, B. Vugrinovich, W. Kataphinan, D. H. Reneker, and P. Wang, "Enzyme-carrying polymeric nanofibers prepared via electrospinning for use as unique biocatalysts," Biotechnology Progress, vol. 18, no. 5, pp. 1027-1032, 2002.

[14] J. W. Goodwin, J. Hearn, C. C. Ho, and R. H. Ottewill, "The preparation and characterisation of polymer latices formed in the absence of surface active agents," Br Polym J, vol. 5, no. 5, pp. 347-362, 1973.

[15] M. M. Bradford, "A rapid and sensitive method for the quantitation of microgram quantities of protein utilizing the principle of protein dye binding," Analytical Biochemistry, vol. 72, no. 1-2, pp. 248-254, 1976.

[16] I. D. Buchanan and J. A. Nicell, "Model development for horseradish peroxidase catalyzed removal of aqueous phenol," Biotechnology and Bioengineering, vol. 54, no. 3, pp. 251-261, 1997.

[17] J. L. Muñoz-Muñoz, F. García-Molina, P. A. García-Ruiz et al., "Enzymatic and chemical oxidation of trihydroxylated phenols," Food Chemistry, vol. 113, no. 2, pp. 435-444, 2009.

[18] F. Quintanilla-Guerrero, M. A. Duarte-Vázquez, B. E. GarcíaAlmendarez, R. Tinoco, R. Vazquez-Duhalt, and C. Regalado, "Polyethylene glycol improves phenol removal by immobilized turnip peroxidase," Bioresource Technology, vol. 99, no. 18, pp. 8605-8611, 2008.

[19] Q. Feng, B. Tang, Q. F. Wei, D. Y. Hou, S. M. Bi, and A. F. Wei, "Preparation of a $\mathrm{Cu}(\mathrm{II})-\mathrm{PVA} / \mathrm{PA} 6$ composite nanofibrous membrane for enzyme immobilization," International Journal of Molecular Sciences, vol. 13, no. 10, pp. 12734-12746, 2012. 

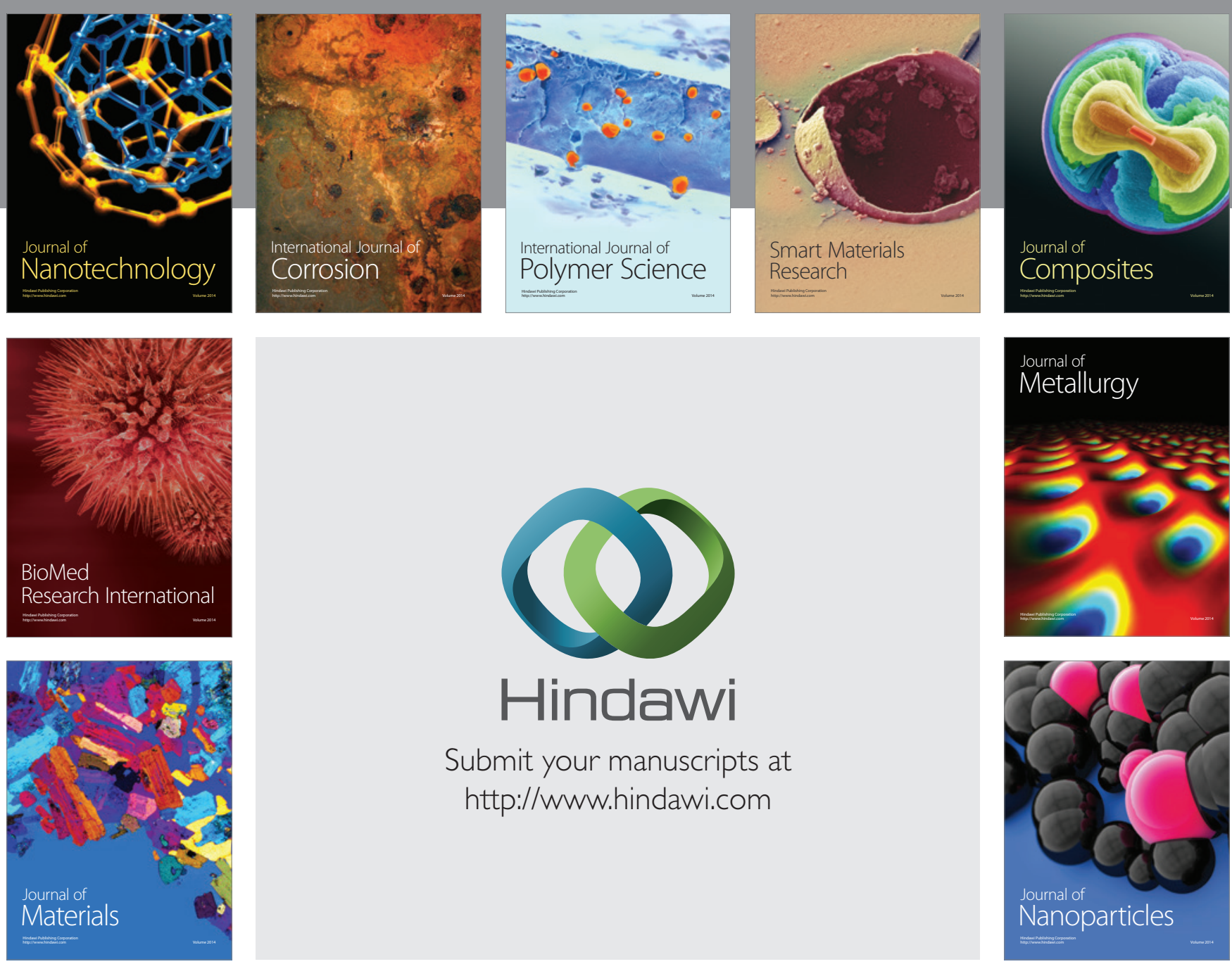

Submit your manuscripts at http://www.hindawi.com
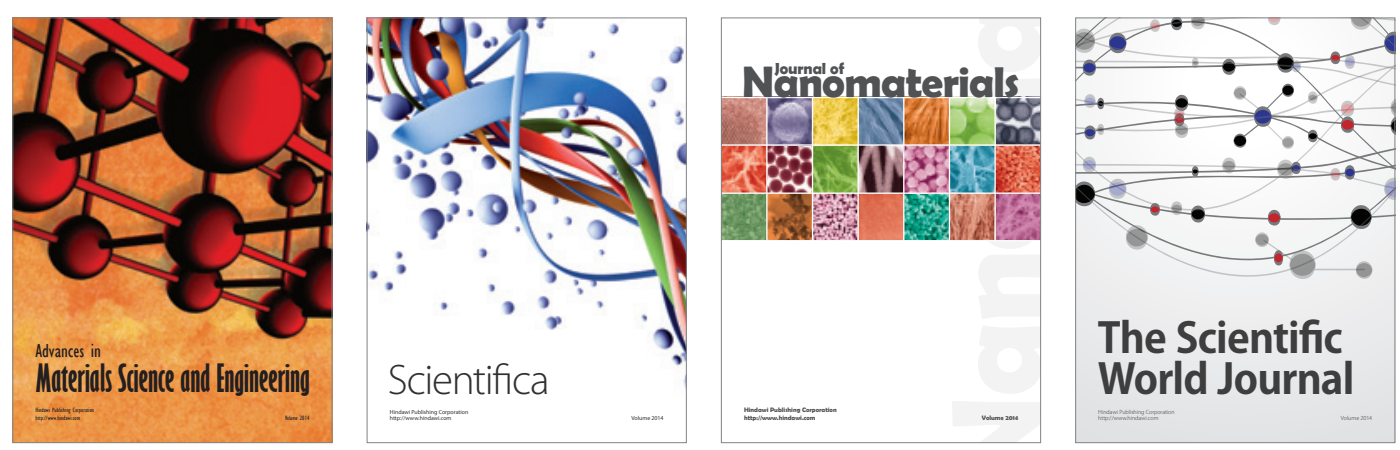

\section{The Scientific World Journal}
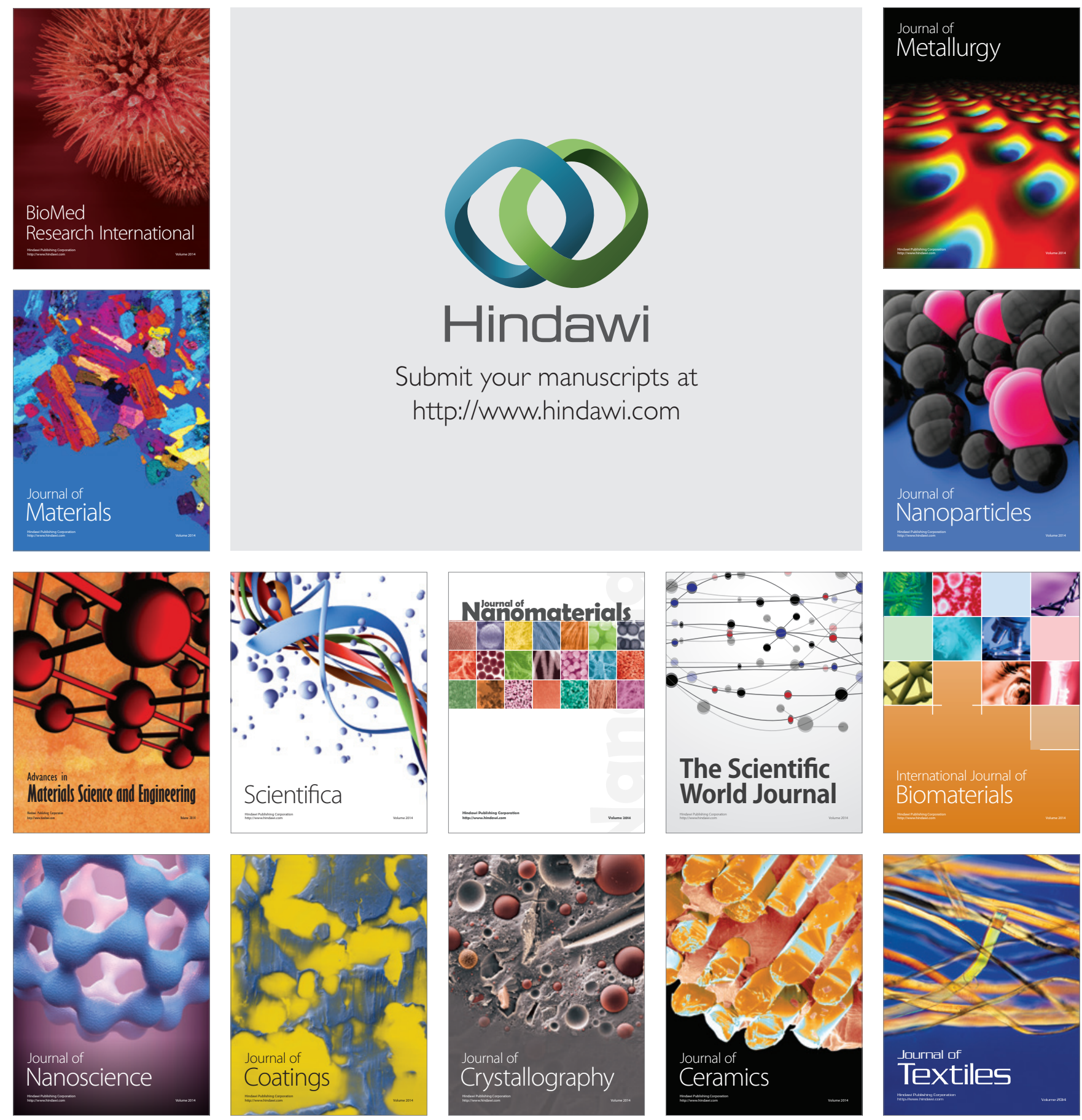